\title{
The Evaluation of the Seismic Vulnerability of Reinforced Concrete Building in Different Areas of Morocco
}

\author{
T. Tbatou ${ }^{1}$, M. Rougui ${ }^{2}$ \\ I (Department of Urban and Environmental Engineering, Higher School of Technology SALE,Morocco) \\ ${ }_{2}^{2}$ (Department of Urban and Environmental Engineering, Higher School of Technology SALE,Morocco)
}

\begin{abstract}
The work is presented in the context of estimating the seismic vulnerability of reinforced concrete building by determining the maximum displacements of all levels of the studied building and stability factors, by comparing the seismic shifts in the three areas of Morocco, using seismic regulations 2000, different vulnerabilities studies allowed us to establish a new concept of the economic impact of the optimal sizing and the estimation of the construction of the building for non-risky areas compared to the critical ones in Morocco.
\end{abstract}

Keywords - Morocco, Vulnerability, Building, RPS2000, Seismic Area

\section{INTRODUCTION}

In seismic codes or regulations, the study of the response of building structures to the effects of earthquakes is conducted using simplified methods based on spectra with response [1], to optimize the seismic design of structures. In addition, the method relies on using a procedure for calculating the maximum displacements of different levels of reinforced concrete building located on a ground referenced by type S1, ordinary class II ,according to the code of Moroccan seismic building RPS 2000 [2], which established a seismic zoning dividing the Moroccan national territory into three zones of seismicity. This zoning up places the province of Al Hoceima, along Agadir and its region, in zone 3 where the degree of seismic risk is the highest in Morocco and the two least risk areas are named zone 2 and 1.

In this essay, we propose an evaluation study of the Arbitration divergence sizing of the structure of the reinforced concrete building, on the economic impact of the construction at the spectrum of seismic elastic response to a relative damping $\xi=5 \%$ applied on a comparison of three seismic zones of Morocco on site type S1 (rock any depth).

\subsection{THE SEISMIC ZONES IN MOROCCO}

\section{ZONING AND SEISMIC STABILITY INDEX}

To simplify the calculation of structural design through large areas of Morocco, the RPS 2000 uses the approach of zones. It is about dividing Morocco into three zones of homogeneous seismicity and having approximately the same level of seismic risk probability of occurrence of $10 \%$ in 50 years.

In each area, the parameters defining the seismic risk, such as the horizontal ground acceleration is considered constant with:

Zone 1: $\quad$ Amax $/ \mathrm{g}=0.01$

Zone 2: $\quad$ Amax/g $=0.08$

Zone 3: $\quad$ Amax $/ g=0.16$

The map of seismic zones of Morocco is shown in Figure 1

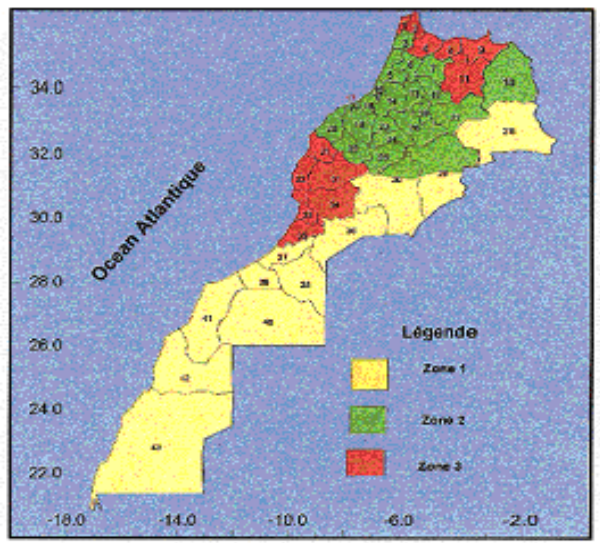

fig1 : Map of the three seismic zones of Morocco 


\subsection{THE INDEX OF STABILITY}

The index of the roll stability in the linear case is represented by the equation [2]:

With:

$$
\begin{gathered}
\boldsymbol{\theta}=\mathbf{K W} \text { Del } / \mathbf{V} \mathbf{h} \\
\mathbf{V}=\mathrm{WASDI} / \mathrm{K}
\end{gathered}
$$

\begin{tabular}{|l|l|}
\hline$\Theta$ & Stability index \\
\hline W & Weight above the floor considered \\
\hline V & Seismic actions at the level considered \\
\hline h & Storey height \\
\hline Del & Relative displacement \\
\hline K & Behavior factor \\
\hline A & Coefficient of acceleration zone \\
\hline S & Coefficient Site \\
\hline D & Dynamic amplification factor given by the amplification spectrum \\
\hline I & Coefficient given priority \\
\hline
\end{tabular}

\section{DESCRIPTION OF THE STUDIED BUILDING}

\section{APPLICATION}

The studied building is made out of reinforced concrete [3] - [4], for residential use (Figure 2), consisting of a ground floor under four floors. The resistant structure is composed of solid slabs of thicknesses $12 \mathrm{~cm}$, the main beams have a section of $(25 \times 45) \mathrm{cm}$, while the two end poles corners of cross have a section of $(25 \times 25 \mathrm{~cm})$ and the other poles are sized by $(30 \times 30) \mathrm{cm}$, the building is located on a soil type $\mathrm{S} 1$. The concrete used is a concrete with a strength of $25 \mathrm{Mpa}$, HA500 steel, the reinforcement of beams and columns is (4.8 $\Phi 14$, 12 and 8). The building is regular (to avoid twisting effect) [5] and sized according to Regulation Moroccan earthquake in 2000 .

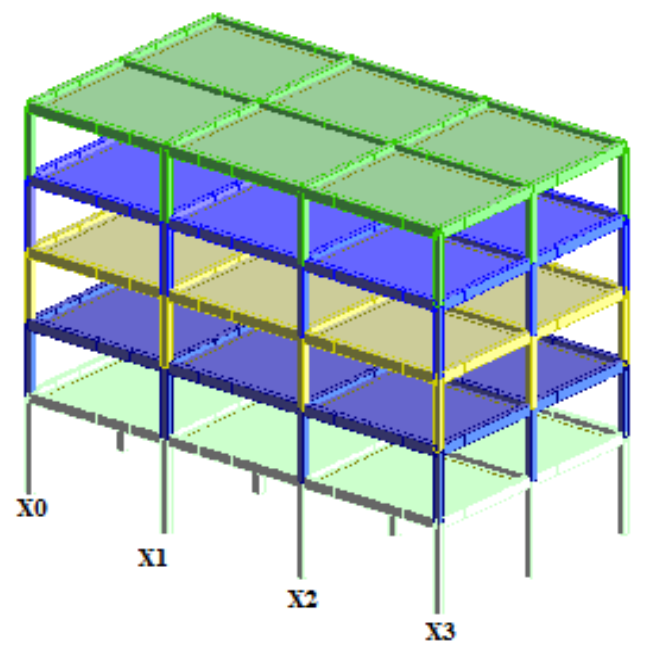

Fig 2 : Model of reinforced concrete building $(\mathrm{R}+4)$

\begin{tabular}{|c|c|c|c|c|c|}
\hline Designation & ground floor & Floor 1 & Floor 2 & Floor 3 & Floor 4 \\
\hline height (m) & 4 & 7 & 10 & 13 & 16 \\
\hline
\end{tabular}

\section{RESULTS}

In order to estimate the dimensions of the design of reinforced concrete building by determining the seismic vulnerability of the building (the movement of floors of the building), an analysis of seismic simulation of three seismic regions based on movement calculations has been carried out by Autodesk software [6] and the application of the horizontal direction of the earthquake is along the axis of $\mathrm{X}$.

\subsection{DisPLACEMENTS}

According to the three seismic zones of Morocco, the displacements obtained for each building height are shown on: Figures 3, 4 and 5. 


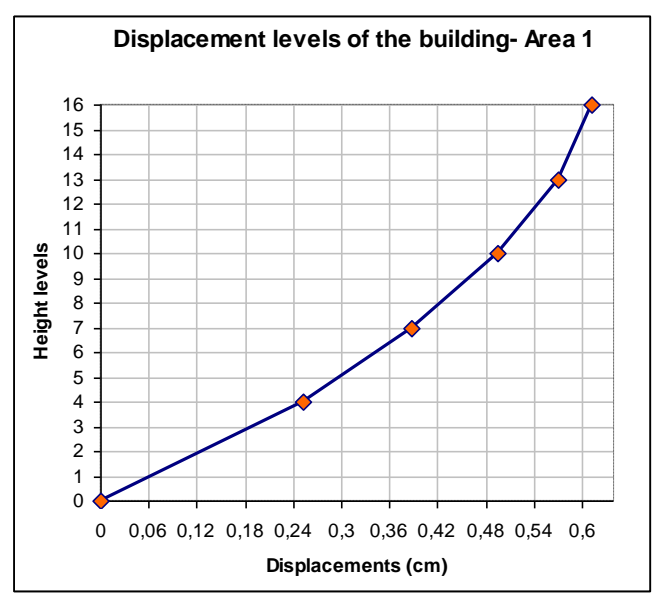

Figure 3 : The maximum displacements of each floor of the building in seismic zone 1

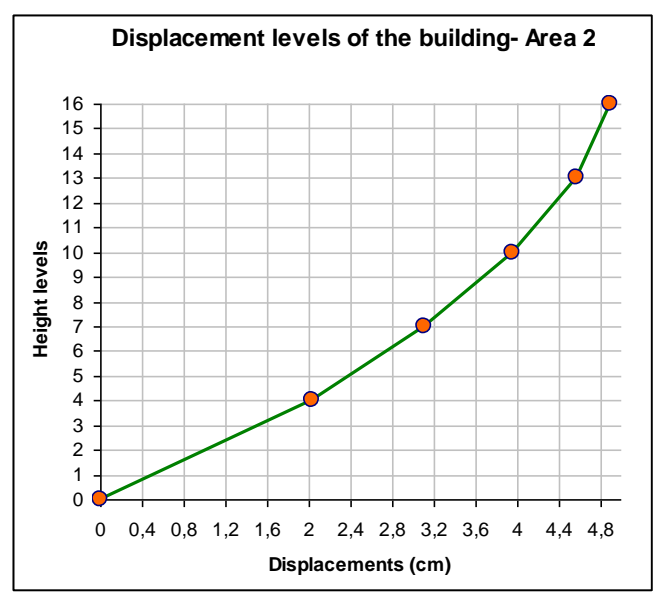

Figure 4 : The maximum displacements of each floor of the building in seismic zone 2

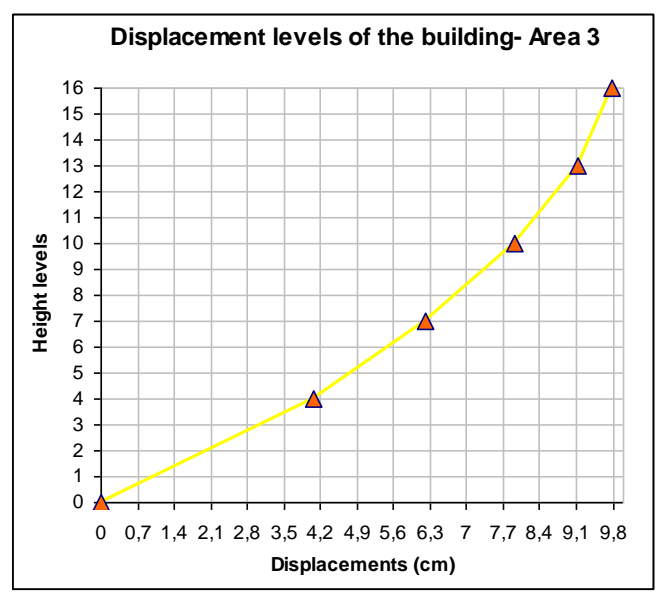

Figure 5 : The maximum displacements of each floor of the building in seismic zone 3

The calculated displacements in the three seismic zones of Morocco show that they are classified according to: Displacement (Area 1) $<$ Displacement (Area 2) $<$ Displacement (Area 3)

Zone 3: The displacements of the upper roof of the building reach $97.87 \mathrm{~mm}$.

Zone 2: The displacements of the upper roof of the building reach $48.94 \mathrm{~mm}$. with $48.93 \mathrm{~mm}$ represents the reduction of the calculated displacement of zone 2 calculated with respect to the zone 3 .

Zone 1: The displacements of the upper roof of the building reach $6.12 \mathrm{~mm}$. With $91.75 \mathrm{~mm}$ represents the reduction of the calculated displacement relative to zone 3 and $42.82 \mathrm{~mm}$ relative to zone 2 . 


\subsection{INTERPRETATION}

Values of the stability index of the structure:

\begin{tabular}{|c|c|c|c|}
\hline Area & 1 & 2 & 3 \\
\hline$\Theta$ & 0,0063 & 0,0507 & 0,1013 \\
\hline
\end{tabular}

It is observed that the calculated stability index $\mathrm{\theta Z1}<\mathrm{\theta Z2}<\mathrm{OZ} 3$ for the same site (S1) and the same structure, This demonstrates that for:

Zone 1: Minimization of $42.82 \mathrm{~mm}$ of displacement is for zone 2, which reduces the risk of this design by $87.50 \%$ compared to zone 2 (gain on the size of the structure).

Zone2: Minimization of $48.93 \mathrm{~mm}$ of displacement is for zone 3, which reduces the risk of this design around 49.99\% compared to zone 3 (sizing optimization).

\section{CONCLUSION}

We notice that the structural design of reinforced concrete building in the seismic zone $\mathrm{Z1}$ is more optimized (with the lowest degree of seismic vulnerability) compared to those made in zone Z2 and Z3. Thus, the design of structures in zone $\mathrm{Z} 2$ is more optimized than the design in zone $\mathrm{Z3}$, which justifies the high cost of construction in the seismic zone Z3 (the most critical area, northern region, Agadir region ... ) of Morocco compared to zone Z1 and Z2.

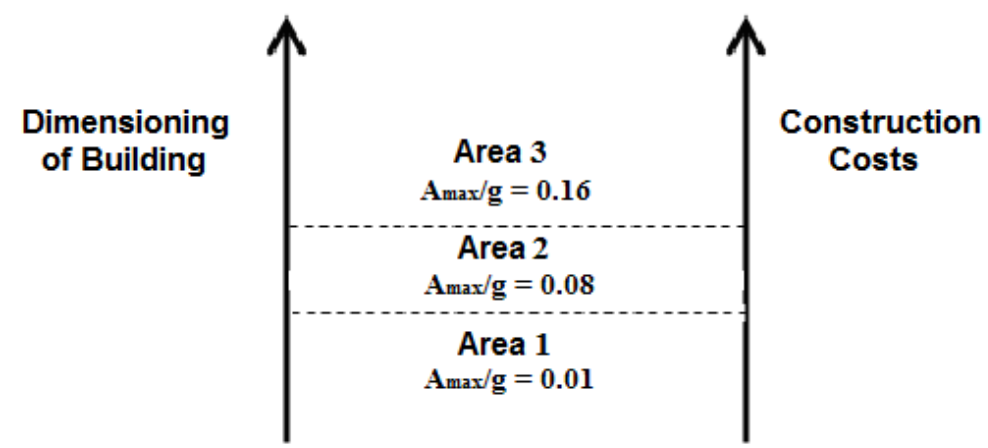

Our perspective on the one hand is to integrate, in Moroccan seismic settlement, an estimation of optimization design of the building at some percentage in seismic zones. This optimization is considered in relation to one of the most critical area with the objective of integrating an impact of economic and technical knowledge for new buildings and those to strengthen.

On the other hand we consider the specifications and designs of intermediates seismic zones between the three areas mentioned by RPS2000, in order to reduce the discrepancy between the design of buildings in different seismic zones of Morocco.

\section{REFERENCE}

[1] Belmouden Y,Analyse spectrale non itérative des oscillateurs simples sous l'action des tremblements de terre, Bull. Lab, Sciences de la Terre, $n^{\circ} 26,2004,1-10$

[2] RPS2000 "seismic Moroccan provisions" published by Ministry of housing 2000.

[3] EN, Eurocode 8. Design of structures for earthquake resistance, Ed. Eyrolles 2004

[4] BAEL 91 modifiées 99,Règles techniques de conception et de calcul des ouvrages et constructions en béton armé suivant la méthode des états limites ,Éd.Eyrolles 2000.

[5] Esteban Sáez.Fernando Lopez-Caballero , Arézou Modaressi-Farahmand-Razavi Structural- Safety, 2011, 51-63.

[6] Autodesk "ROBOBAT" Computer and structures, tutorial-sismic simulation analysis. 